\title{
Jaringan Syaraf Tiruan Backpropagation untuk Klasifikasi Data Tilang Berdasarkan Jenis Pelanggaran
}

\author{
Mhd. Denry Aruna Nasution' ${ }^{1}$, Jaya Tata Hardinata ${ }^{2}$, Irfan Sudahri Damanik ${ }^{3}$ \\ STIKOM Tunas Bangsa \\ rendydevon@gmail.com ${ }^{1}$,jayatatahardinata@gmail.com², irfansudahri@gmail.com³
}

\begin{abstract}
Proof of violation (ticketing) applies to every person who commits a violation in traffic. The high level of violations that occur also results in the ticket data stored at the Simalungun District Prosecutor's Office becoming obstacles such as the excess capacity of the courtroom.In the ticketing file there are several important points that explain the details of the ticket, such as the type of evidence, vehicle, article, attendance at the trial, and the type of operation performed.Classification can be used as an alternative in the division of the ticketing schedule.The ticket classification in this study uses the Backpropagation method.The target of the expected backpropagation classification is a type of minor and severe violation. The best level of accuracy obtained from this study is $95.0 \%$.
\end{abstract}

Keywords : backpropagation, classification, ticket, the simalungun state prosecutor's office.

Abstrak - Bukti pelanggaran (tilang) diberlakukan kepada setiap orang yang melakukan pelanggaran dalam berlalu lintas.Tingginya tingkat pelanggaran yang terjadi juga mengakibatkan data tilang yang tersimpan pada Kejaksaan Negeri Simalungun menjadi hambatan seperti kelebihan kapasitas ruang sidang. Dalam berkas tilang terdapat beberapa pokok penting yang menjelaskan detail tentang tilang seperti jenis barang bukti, kendaraan, pasal, kehadiran pada saat sidang, dan jenis operasi yang dilakukan. Klasifikasi dapat digunakan sebagai alternatif dalam pembagian jadwal sidang tilang.Klasifikasi tilang pada penelitian ini menggunakan metode Backpropagation.Target dari klasifikasi backpropagation yang diharapkan adalah jenis pelanggaran ringan dan berat.Tingkat akurasi terbaik yang diperoleh dari penelitian ini adalah sebesar $95.0 \%$.

Kata Kunci : backpropagation, klasifikasi, tilang, kejaksaan Negeri Simalungun.

\section{PENDAHULUAN}

Meningkatnya pelanggaran lalu lintas di Indonesia, khususnya wilayah kerja Kabupaten Simalungun mengakibatkan menumpuknya jumlah data di kantor kejaksaan yang tidak tertata dengan baik secara signifikan mempengaruhi kemampuan kerja para staff dalam mengolah data, pemberkasan, dan terutama untuk penjadwalan sidang para jaksa. Hal ini dapat diantisipasi dengan dilakukan pembagian pada saat persidangan.Salah satu metode yang dapat digunakan untuk masalah ini adalah teknik klasifikasi data dengan menggunakan metode jaringan syaraf tiruan backpropagation.Penelitian diharapkan dapat memberikan kontribusi keilmuan teknologi informasi untuk membantu kerja pihak - pihak Kejaksaan Negeri Simalungun. 


\section{METODOLOGI PENELITIAN}

\subsection{TinjauanPustaka}

Kecerdasan buatan atau artificialintelligence (AI) merupakan salah satu bagian ilmu komputer yang membuat mesin (komputer) dapat melakukan pekerjaan seperti dan sebaik yang dilakukan oleh manusia[1]-[3]. Salah satu ilmu pengetahuan AI adalah Jaringan Syaraf Tiruan.Jaringan Syaraf Tiruan adalah merupakan salah satu representasi buatan dari otak manusia yang selalu mencoba untuk mensimulasikan proses pembelajaran pada otak manusia tersebut. Istilah buatan disini digunakan karena jaringan syaraf ini diimplemintasikan dengan menggunakan program komputer yang mampu menyelesaikan sejumlah proses perhitungan selama proses pembelajaran. JST merepresentasikan dan mencoba mensimulasikan proses yang dilakukan otak manusia. Tiruan yang dimaksudkan adalah proses perealisasian dengan menggunakan sistem komputerisasi yang dapat menyelesaikan berbagai proses perhitungan.Penelitian dilakukan dengan menggunakan metode backpropagation.

Backpropagation merupakan algoritma pembelajaran yang terawasi dan biasanya digunakan oleh perceptron dengan banyak lapisan untuk mengubah bobot-bobot yang terhubung dengan neuron-neuron yang ada pada lapisan tersembunyinya[4]-[10]. Algoritma backpropagation menggunakan error output untuk mengubah nilai bobot-bobotnya dalam arah mundur (backward). Untuk mendapatkan error ini, tahap perambatan maju (forwardpropagation) harus dikerjakan terlebih dahulu[11]. Dalam jaringan, selain terdapat unit input, unit tersembunyi (hiddenunits) dan output juga terdapat bias yang diberikan pada unitunit tersembunyi dan output[12].

\subsection{Metode Pengumpulan Data}

a) Studi Literatur, penulis mempelajari cara dan pola pengumpulan data sebaikbaiknya dengan pedoman-pedoman yang terdapat pada buku-buku, materi ajar dan penelitian terdahulu dari bagian perpustakaan agar tidak salah dalam pengumpulan data yang akan digunakan.

b) Penelitian Lapangan, penulis mengumpulkan data dilapangan dengan beberapa cara, yaitu :

1) Wawancara, penulis melakukan tanya jawab terlebih dahulu kepada pihak yang bersangkutan (bagian tilang) tentang bagaimana data tentang tilang dapat diperoleh dan apakah data tersebut bisa digunakan untuk penelitian.

2) Observasi, penulis dalam mengumpulkan data melakukan pengawasan terhadap setiap alur penerimaan data tilang dari setiap jaksa yang melaporkan kepada bagian tilang, serta memilah data mana yang tepat digunakan sebagai sumber data untuk penelitian.

c) Penulis juga menggunakan data sekunder dari register tilang Kejaksaan Negeri Simalungun yang biasa disebut Verstek berbentuk file Microsoft office excel tahun 2018.

Terdapat 5 jenis atribut dari verstek yang dapat digunakan untuk mencapai target / hasil dari algoritma, yaitu :

1. Barang Bukti, 
2. Kendaraan,

3. Pasal,

4. Kehadiran Pada Saat Sidang,

5. Jenis Operasi.

Tabel 1. Data Tilang Kejaksaan Negeri Simalungun Desember 2018

\begin{tabular}{|c|l|l|l|l|l|l|}
\hline No & Nama & $\begin{array}{c}\text { Barang } \\
\text { Bukti }\end{array}$ & Kendaraan & \multicolumn{1}{|c|}{ Pasal } & Kehadiran & $\begin{array}{l}\text { Jenis } \\
\text { Operasi }\end{array}$ \\
\hline 1 & Pelanggar 1 & SIM C & $\begin{array}{l}\text { Sepeda } \\
\text { Motor }\end{array}$ & $\begin{array}{l}\text { Pasal 293 Ayat (2) Jo Pasal } \\
\text { 107 Ayat (2) }\end{array}$ & Hadir & Zebra \\
\hline 2 & Pelanggar 2 & SIM A & Mobil Pribadi & $\begin{array}{l}\text { Pasal 288 Ayat (1) Jo Pasal } \\
\text { 70 Ayat (2) }\end{array}$ & Diwakilkan & Zebra \\
\hline 3 & Pelanggar 3 & STNK & $\begin{array}{l}\text { Mobil Pick } \\
\text { Up }\end{array}$ & $\begin{array}{l}\text { Pasal 288 Ayat (3) Jo Pasal } \\
\text { 106 Ayat (5) Huruf C }\end{array}$ & Hadir & Zebra \\
\hline 4 & Pelanggar 4 & SIM A & Mobil Pribadi & $\begin{array}{l}\text { Pasal 289 Jo Pasal 106 Ayat } \\
\text { (6) }\end{array}$ & Hadir & Zebra \\
\hline 5 & Pelanggar 5 & SIM C & $\begin{array}{l}\text { Sepeda } \\
\text { Motor }\end{array}$ & $\begin{array}{l}\text { Pasal 293 Ayat (2) Jo Pasal } \\
\text { 107 Ayat (2) }\end{array}$ & Hadir & Lintas \\
\hline
\end{tabular}

Data diatas merupakan sampel data sekunder dari bagian tilang Kejaksaan Negeri Simalungun.Namun untuk dapat dimasukkan kedalam sistem, perlu dilakukan tahap normalisasi data agar data dapat dibaca oleh sistem.Data diatas dinormalisasikan dengan menginisialisasikan setiap nilai atribut yang ada menjadi angka karena sistem yang digunakan hanya dapat membaca angka. Atribut barang bukti, kendaraan, pasal, kehadiran, jenis operasi diubah menjadi $\mathrm{x}_{1}, \mathrm{x}_{2}, \mathrm{x}_{3}, \mathrm{X}_{4}$, dan $\mathrm{x}_{5}$. Dan selanjutnya dimasukkan ke persamaan berikut[13]-[26]:

$x^{1}=\frac{0.8(x-a)}{b-a}+0.1$

Tabel 2. Inisialisasi Data

\begin{tabular}{|c|c|c|c|c|c|c|c|}
\hline \multirow{2}{*}{ No } & \multirow{2}{*}{ Nama } & \multicolumn{5}{|c|}{ Masukan } & \multirow{2}{*}{ Target } \\
\cline { 3 - 7 } & & $\mathbf{x}_{\mathbf{1}}$ & $\mathbf{x}_{\mathbf{2}}$ & $\mathbf{x}_{\mathbf{3}}$ & $\mathbf{x}_{\mathbf{4}}$ & $\mathbf{x}_{\mathbf{5}}$ & \\
\hline 1 & Pelanggar 1 & 3 & 1 & 8 & 1 & 2 & 1 \\
\hline 2 & Pelanggar 2 & 1 & 2 & 5 & 2 & 2 & 2 \\
\hline 3 & Pelanggar 3 & 4 & 4 & 5 & 1 & 2 & 2 \\
\hline 4 & Pelanggar 4 & 1 & 2 & 6 & 1 & 2 & 1 \\
\hline 5 & Pelanggar 5 & 3 & 1 & 8 & 1 & 1 & 1 \\
\hline
\end{tabular}

Target penelitian merupakan jenis pelanggaran yang dilakukan.Jenis pelanggaran dibagi menjadi dua yaitu ringan dan berat, pelanggaran ringan disimbolkan dengan angka 1, dan pelanggaran berat disimbolkan dengan angka 2 . Ada beberapa tahapan yang akan dilakukan dalam algoritma backpropagation secara manual dengan fungsi aktivasi sigmoid, yaitu sebagai berikut:

a) Inisialisasi (inisialisation), yaitu tahap dimana tiap variabel nilai masukan, bobot, nilai keluaran yang diharapkan, learning rate, dan nilai - nilai lainnya didefinisikan.

b) Aktivasi (activation), yaitu tahap perhitungan terhadap nilai keluaran pada lapisan tersembunyi dan perhitungan terhadap nilai keluaran pada lapisan keluaran. 
c) Pelatihan Bobot (weighttraining), yaitu tahap perhitungan nilai error pada lapisan keluaran dan perhitungan error terhadap nilai keluaran pada lapisan keluaran.

d) Iterasi (iteration), yaitu tahap akhir dalam pengujian, dimana jika error yang diharapkan belum ditemukan, maka kembali ke tahap aktivasi.

\subsection{TahapanPenelitian}

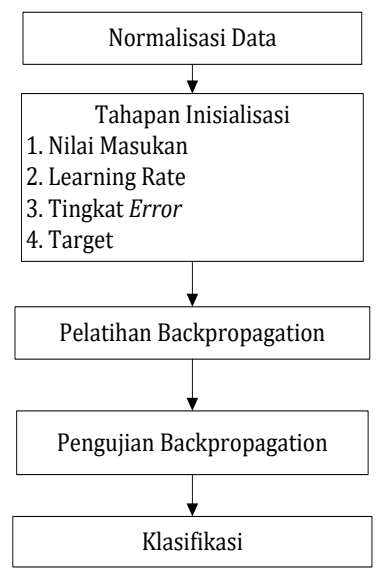

Gambar 1. flowchart Tahapan Penelitian

Dari data yang terlah dinormalisasi, kita dapat langsung menentukan pola yang akan digunakan dalam proses pelatihan maupun perngujian. Data selanjutnya dimasukkan kedalam sistem, dimulai dengan proses pelatihan, pengujian akurasi, dan proses pengujian hingga memberikan keluaran berupa data/informasi. Data / informasi hasil keluaran dapat digunakan untuk ditindak lanjuti maupun diolah kembali sebagai data untuk penelitian lainnya. Perancangan penelitian ini penulis visualisasikan dalam bentuk flowchart gambar dibawah ini :

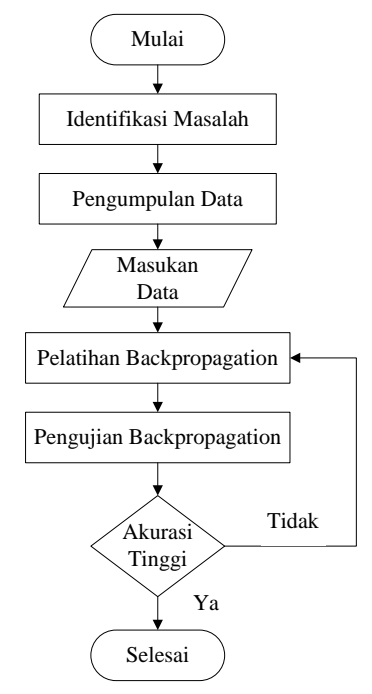

Gambar 2. flowchart Perencanaan Penelitian 
Model arsitektur jaringan pedoman adalah dengan 3 lapisan yang terdiri dari 5 lapisan masukan, 3 lapisan tersembunyi, dan 2 lapisan keluaran. Seperti pada gambar dibawah :

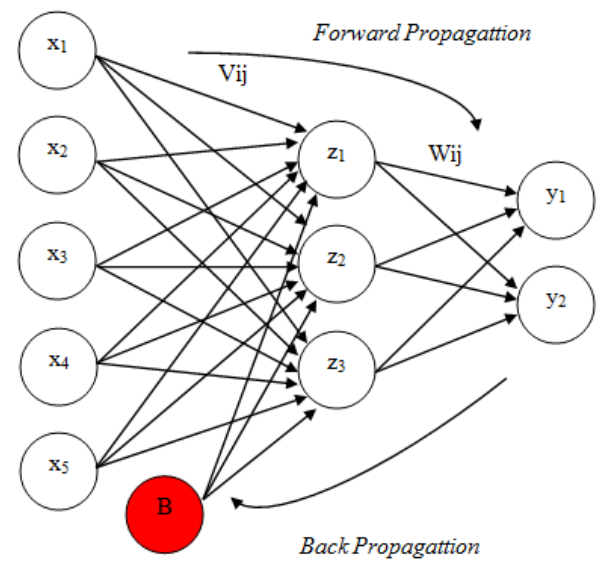

Gambar 3. Arsitektur Backpropagation

Keterangan :

$\mathrm{x}_{1}-\mathrm{x}_{5}$ : Lapisan masukan

Vij : Bobot ke- pada lapisan tersembunyi

Wij : Bobot ke- pada lapisan keluaran

$\mathrm{z}_{1}-\mathrm{z}_{3}$ : Lapisan Tersembunyi

$\mathrm{y}_{1}-\mathrm{y}_{2}$ : Lapisan Keluaran

B : Bias

\section{HASIL DAN PEMBAHASAN}

Jaringan syaraf tiruan pada data tilang sepenuhnya dikerjakan sesuai dengan algoritma backpropagation dimana hasil yang dikeluarkan memberikan langsung tingkat akurasi dari pola jaringan, banyaknya perulangan yang dilakukan, learning rate, dan parameter goal yang digunakan.Pola disini terdiri dari lapisan masukan, lapisan tersembunyi, dan lapisan keluaran. Data pelatihan dan pengujian akan langsung dikalkulasikan sesuai dengan perintah yang dimasukkan pada command windowmatlab R2011b.

\subsection{Pelatihan Dan Pengujian Data Dengan Pola 5-3-2}

a) Data yang ada pada tabel 4.1 dan 4.2 diolah dengan matlab dengan pola 5-3Adapun proses pengolahan data dengan matlab sebagai berikut :

1) Mengatur Lokasi Data Yang Akan Digunakan

$>>$ filename $=$ 'Data.xlsx';

$>>$ sheet $=4$;

$>>$ xlRange = 'A1:CV5';

Ketiga baris diatas merupakan perintah untuk membaca data pelatihan sebanyak 50 pada file microsoft excel bernama Data.xlsx di sheet ke 4 dengan range $\mathrm{x}_{1}$ dari kolom $\mathrm{A} 1$ sampai CV5.

$>$ filename = 'Data.xlsx';

$>>$ sheet $=5$;

$>>$ xlRange $=$ 'A1:CV2'; 
Ketiga baris diatas merupakan perintah untuk membaca data pengujian sebanyak 50 pada file microsoft excel bernama Data.xlsx di sheet ke 5 dengan range $\mathrm{x}_{1}$ dari kolom $\mathrm{A} 1$ sampai $\mathrm{CV} 2$.

2) Menetapkan Parameter Yang Digunakan.

Langkah awal yang perlu dilakukan adalah menentukan parameter yang akan digunakan pada proses pelatihan maupun pengujian. Beberapa parameter yang ditentukan adalah sebagai berikut :

$>$ > hiddenLayerSize $=3$;

Perintah ini untuk membatasi jumlah lapisan tersembunyi yang digunakan pada pola jaringan backpropagation.

>>net.trainParam.epochs = 10000;

Parameter ini menentukan jumlah epoch maksimum pada pelatihan dan pengujian.

$>>$ net.trainParam.lr $=0.1$;

Learning rate yang dimasukkan pada pola 5-3-2 adalah 0.1, $>>$ net.trainParam.goal $=0.03$;

Parameter ini digunakan untuk menentukan batas nilai MSE agar iterasi dihentikan. Iterasi akan berhenti jika $M S E<$ batas yang ditentukan dalam net.trainParam.goal atau jumlah epoch yang telah ditentukan dalam net.trainParam.epochs.

$>>$ net.divideParam.trainRatio $=50 / 100$; dan,

$>>$ net.divideParam.testRatio $=50 / 100$;

Parameter ini membagi data tilang yang ada menjadi data pelatihan dan data pengujian.

3) Keluaran Yang Dihasilkan

$>>$ [net,tr] = train(net,Data_Training,Data_Target);

Setelah parameter pelatihan dan pengujian dimasukkan, selanjutnya dilakukan running pada matlab R2011b. Gambar berikut merupakan hasil pelatihan dan pengujian dengan pola 5-3-2 :

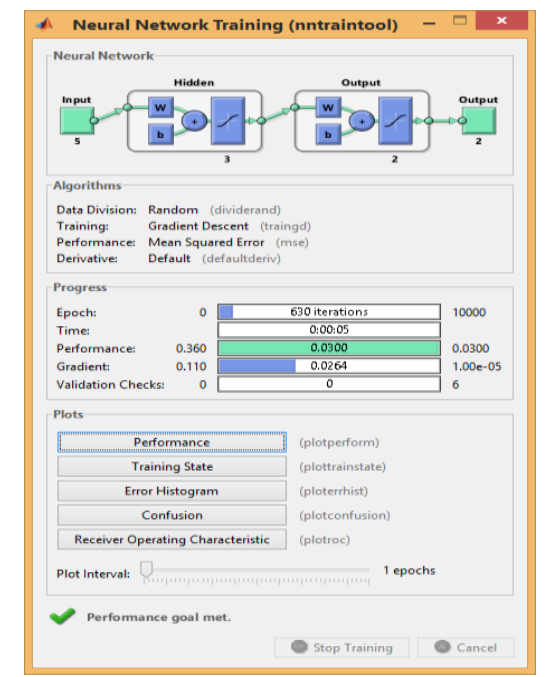

Gambar 4. Hasil Pelatihan dan Pengujian Pola 5-3-2 
Gambar 4 menjelaskan hasil dari pelatihan dan pengujian dengan rincian sebagai berikut :

1. Proses pelatihan berhenti pada iterasi 630 dari 10000 iterasi yang diinginkan.

2. Waktu untuk mencapai iterasi 10000 adalah 5 detik.

3. Error yang dihasilkan dari parameter tersebut yaitu 0.03 .

4. Gradient yang dihasilkan adalah 0.0264 .

Pengenalan pola yang ditentukan harus sesuai dengan yang dimasukkan dan diproses oleh matlab, hal ini dapat dilihat pada hasil pengenalan pola matlab pada gambar berikut :

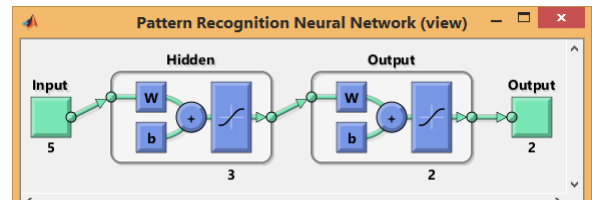

\section{Gambar 5. PatternRecognition Pola 5-3-2}

Hasil persentase akurasi juga dilihat pada Confusion dari matlab yang menunjukkan akurasi sebesar $95.0 \%$ pada gambar dibawah ini.

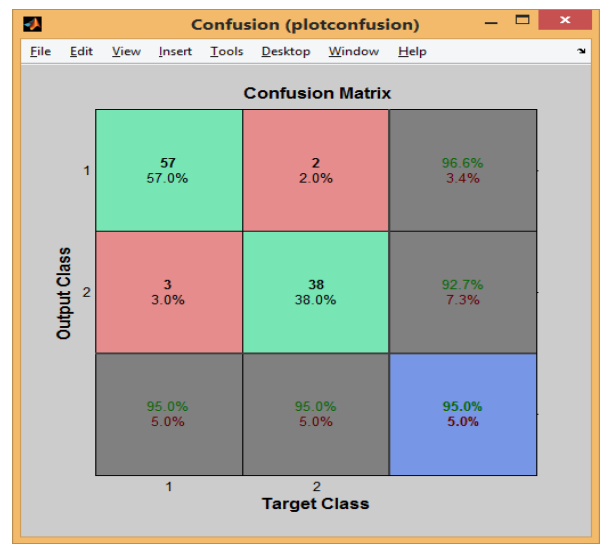

Gambar 6. Confusion Pola 5-3-2

Grafik performance pada pola latihan 5-3-2 dapat dilihat pada gambar 8 berikut ini

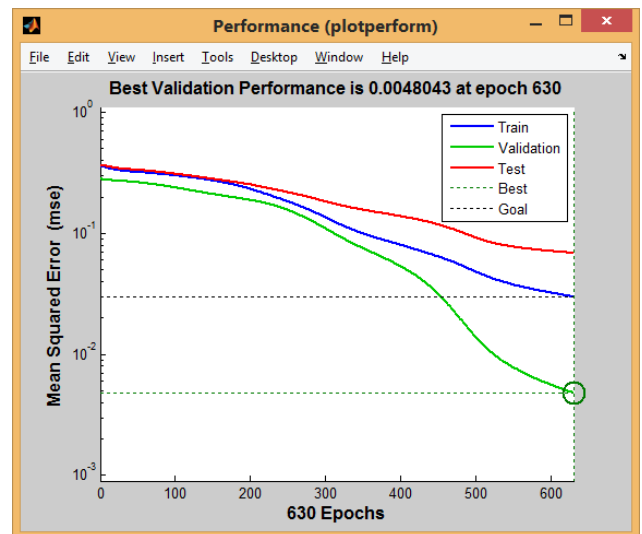

Gambar 7. Grafik performance 5-3-2 
Untuk lebih jelasnya, hasil klasifikasi dapat dilihat pada tabel 3 dibawah ini :

Tabel 3. Tabel Hasil Klasifikasi Pola 5-3-2 Lr 01 Goal 0.3

\begin{tabular}{|c|c|c|c|c|c|c|c|c|c|}
\hline \multirow[t]{2}{*}{ No } & \multirow{2}{*}{ Nama } & \multicolumn{5}{|c|}{ Masukan } & \multirow[t]{2}{*}{ Target } & \multirow[t]{2}{*}{ Output } & \multirow[t]{2}{*}{ Hasil } \\
\hline & & $\mathrm{x}_{1}$ & $\mathrm{X}_{2}$ & $\mathrm{x}_{3}$ & $\mathrm{X}_{4}$ & $\mathrm{X}_{5}$ & & & \\
\hline 1 & Pelanggar 1 & 3 & 1 & 8 & 1 & 2 & 1 & 1 & True \\
\hline 2 & Pelanggar 2 & 1 & 2 & 5 & 2 & 2 & 2 & 1 & False \\
\hline 3 & Pelanggar 3 & 4 & 4 & 5 & 1 & 2 & 2 & 2 & True \\
\hline 4 & Pelanggar 4 & 1 & 2 & 6 & 1 & 2 & 1 & 1 & True \\
\hline 5 & Pelanggar 5 & 3 & 1 & 8 & 1 & 1 & 1 & 1 & True \\
\hline
\end{tabular}

\subsection{Perbandingan Akurasi Pola - Pola Jaringan.}

Dari 3 pola arsitektur jaringan yang ada, Akurasi terbaik yang diperoleh adalah sebesar $95.0 \%$ dan akurasi terendah adalah $69.0 \%$ sebagaimana dijelaskan pada gambar 9.

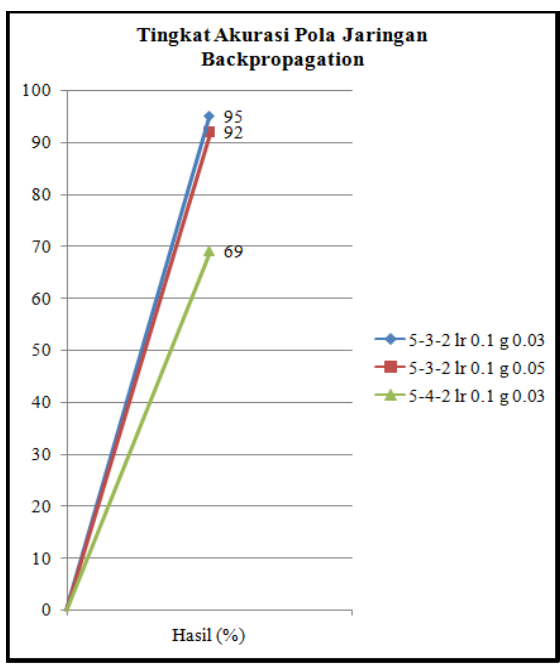

Gambar 8. Grafik Tingkat Akurasi Pola Jaringan Backpropagation

\section{KESIMPULAN}

Kesimpulan yang dapat diambil setelah melakukan proses pelatihan dan pengujian jaringan syaraf tiruan backpropagation pada data tilang Kejaksaan Negeri Simalungun adalah sebagai berikut:

a) Tahap algoritma backpropagation terdiri dari 2 (dua) bagian yaitu proses pelatihan dan proses pengujian. Data yang ada sebanyak 100 unit data, dibagi menjadi 2 (dua) yaitu 50 (lima puluh) unit data pelatihan dan 50 (lima puluh) unit data pengujian. Data yang ada dimasukkan kedalam pola jaringan yang terdiri dari lapisan masukan, lapisan tersembunyi, lapisan keluaran, learningrate dan tingkat error. Pola yang terdapat pada penelitian ini adalah pola 5-3-2 learning-rate 0.1 goal 0.3 , pola 5-3-2 learning-rate 0.1 goal 0.5 , dan pola 5-4-2 learning-rate 0.1 goal 0.3 .

b) Hasil akurasi terbaik yang diperoleh adalah dengan menggunakan pola 5-3-2 learning-rate 0.1 goal 0.3 dengan persentase akurasi $95.0 \%$. 


\section{DAFTAR PUSTAKA}

[1] A. Wanto and A. P. Windarto, "Analisis Prediksi Indeks Harga Konsumen Berdasarkan Kelompok Kesehatan Dengan Menggunakan Metode Backpropagation," Jurnal \& Penelitian Teknik Informatika Sinkron, vol. 2, no. 2, pp. 37-44, 2017.

[2] A. Wanto, A. P. Windarto, D. Hartama, and I. Parlina, "Use of Binary Sigmoid Function And Linear Identity In Artificial Neural Networks For Forecasting Population Density," International Journal Of Information System \& Technology, vol. 1, no. 1, pp. 43-54, 2017.

[3] A. Wanto, M. Zarlis, Sawaluddin, and D. Hartama, "Analysis of Artificial Neural Network Backpropagation Using Conjugate Gradient Fletcher Reeves in the Predicting Process," Journal of Physics: Conference Series, vol. 930, no. 1, pp. 1-7, 2017.

[4] S. P. Siregar and A. Wanto, "Analysis of Artificial Neural Network Accuracy Using Backpropagation Algorithm In Predicting Process (Forecasting)," International Journal of Information System \& Technology, vol. 1, no. 1, pp. 34-42, 2017.

[5] J. R. Saragih, M. Billy, S. Saragih, and A. Wanto, "Analisis Algoritma Backpropagation Dalam Prediksi Nilai Ekspor (Juta USD)," Jurnal Pendidikan Teknologi dan Kejuruan, vol. 15, no. 2, pp. 254-264, 2018.

[6] E. Hartato, D. Sitorus, and A. Wanto, "Analisis Jaringan Saraf Tiruan Untuk Prediksi Luas Panen Biofarmaka di Indonesia," Jurnal semanTIK, vol. 4, no. 1, pp. 49-56, 2018.

[7] S. Setti and A. Wanto, "Analysis of Backpropagation Algorithm in Predicting the Most Number of Internet Users in the World," JOIN (Jurnal Online Informatika), vol. 3, no. 2, pp. 110-115, 2018.

[8] R. E. Pranata, S. P. Sinaga, and A. Wanto, "Estimasi Wisatawan Mancanegara Yang Datang ke Sumatera Utara Menggunakan Jaringan Saraf," Jurnal semanTIK, vol. 4, no. 1, pp. 97-102, 2018.

[9] A. A. Fardhani, D. Insani, N. Simanjuntak, and A. Wanto, "Prediksi Harga Eceran Beras Di Pasar Tradisional Di 33 Kota Di Indonesia Menggunakan Algoritma Backpropagation," Jurnal Infomedia, vol. 3, no. 1, pp. 25-30, 2018.

[10] J. Wahyuni, Y. W. Paranthy, and A. Wanto, "Analisis Jaringan Saraf Dalam Estimasi Tingkat Pengangguran Terbuka Penduduk Sumatera Utara," Jurnal Infomedia, vol. 3, no. 1, pp. 18$24,2018$.

[11] D. Rahayu, R. C. Wihandika, and R. S. Perdana, "Implementasi Metode Backpropagation Untuk Klasifikasi Kenaikan Harga Minyak Kelapa Sawit," Jurnal Pengembangan Teknologi Informasi dan Ilmu Komputer, vol. 2, no. 4, pp. 1547-1552, 2018.

[12] T. Brian, "Analisis Learning Rates Pada Algoritma Backpropagation Untuk Klasifikasi Penyakit Diabetes," Jurnal Ilmiah Edutic, vol. 3, no. 1, pp. 21-27, 2016.

[13] A. Wanto et al., "Levenberg-Marquardt Algorithm Combined with Bipolar Sigmoid Function to Measure Open Unemployment Rate in Indonesia," in Conference Paper, 2018, pp. 1-7.

[14] I. A. R. Simbolon, F. Yatussa'ada, and A. Wanto, "Penerapan Algoritma Backpropagation dalam Memprediksi Persentase Penduduk Buta Huruf di Indonesia," Jurnal Informatika Upgris, vol. 4, no. 2, pp. 163-169, 2018.

[15] S. P. Siregar, A. Wanto, and Z. M. Nasution, "Analisis Akurasi Arsitektur JST Berdasarkan Jumlah Penduduk Pada Kabupaten / Kota di Sumatera Utara," in Seminar Nasional Sains \& Teknologi Informasi (SENSASI), 2018, pp. 526-536.

[16] A. Wanto, “Optimasi Prediksi Dengan Algoritma Backpropagation Dan Conjugate Gradient Beale-Powell Restarts," Jurnal Teknologi dan Sistem Informasi, vol. 3, no. 3, pp. 370-380, Jan. 2018.

[17] B. K. Sihotang and A. Wanto, "Analisis Jaringan Syaraf Tiruan Dalam Memprediksi Jumlah Tamu Pada Hotel Non Bintang," Jurnal Teknologi Informasi Techno, vol. 17, no. 4, pp. 333346, 2018.

[18] M. A. P. Hutabarat, M. Julham, and A. Wanto, "Penerapan Algoritma Backpropagation Dalam Memprediksi Produksi Tanaman Padi Sawah Menurut Kabupaten/Kota di Sumatera Utara," Jurnal semanTIK, vol. 4, no. 1, pp. 77-86, 2018.

[19] Y. Andriani, H. Silitonga, and A. Wanto, "Analisis Jaringan Syaraf Tiruan untuk prediksi volume ekspor dan impor migas di Indonesia," Register - Jurnal Ilmiah Teknologi Sistem Informasi, vol. 4, no. 1, pp. 30-40, 2018. 
[20] A. Wanto, "Penerapan Jaringan Saraf Tiruan Dalam Memprediksi Jumlah Kemiskinan Pada Kabupaten/Kota Di Provinsi Riau," Kumpulan jurnaL Ilmu Komputer (KLIK), vol. 5, no. 1, pp. 61-74, 2018.

[21] I. S. Purba and A. Wanto, "Prediksi Jumlah Nilai Impor Sumatera Utara Menurut Negara Asal Menggunakan Algoritma Backpropagation," Jurnal Teknologi Informasi Techno, vol. 17, no. 3, pp. 302-311, 2018.

[22] A. Wanto, "Prediksi Angka Partisipasi Sekolah dengan Fungsi Pelatihan Gradient Descent With Momentum \& Adaptive LR," Jurnal Ilmu Komputer dan Informatika (ALGORITMA), vol. 3, no. 1, pp. 9-20, 2019.

[23] N. Nasution, A. Zamsuri, L. Lisnawita, and A. Wanto, "Polak-Ribiere updates analysis with binary and linear function in determining coffee exports in Indonesia," IOP Conference Series: Materials Science and Engineering, vol. 420, no. 12089, pp. 1-9, 2018.

[24] A. Wanto, "Prediksi Produktivitas Jagung Indonesia Tahun 2019-2020 Sebagai Upaya Antisipasi Impor Menggunakan Jaringan Saraf Tiruan Backpropagation," SINTECH (Science and Information Technology), vol. 1, no. 1, pp. 53-62, 2019.

[25] B. Febriadi, Z. Zamzami, Y. Yunefri, and A. Wanto, "Bipolar function in backpropagation algorithm in predicting Indonesia's coal exports by major destination countries," IOP Conference Series: Materials Science and Engineering, vol. 420, no. 12089, pp. 1-9, 2018.

[26] A. Wanto et al., "Analysis of Standard Gradient Descent with GD Momentum And Adaptive LR for SPR Prediction," 2018, pp. 1-9. 